\title{
STUDY ON BIOROCK® TECHNIQUE USING THREE DIFFERENT ANODE MATERIALS (MAGNESIUM, ALUMINUM, AND TITANIUM)
}

\author{
Neviaty P. Zamani ${ }^{1 *}$, Ramadian Bachtiar ${ }^{1}$, Hawis H. Madduppa ${ }^{1}$, Jhoni Wahyu \\ Adi $^{2}$, Jeddah Isnul ${ }^{1}$, Muhamad Iqbal ${ }^{1}$, and Beginer Subhan ${ }^{1}$ \\ 1. Department of Marine Science and Technology, Faculty of Fisheries and Marine Science, Bogor \\ Agricultural University, Jl. Agatis No.1, Bogor 16680, Indonesia \\ 2. Department of Metallurgy and Materials, Faculty of Mathematics and Science, University of Indonesia, \\ Depok 16424, Indonesia \\ ${ }^{*}$ E-mail: np_zamani@yahoo.com
}

\begin{abstract}
Biorock ${ }^{\circledR}$ technique is the earliest methods to rehabilitate the damage of coral reef ecosystem. Its improvement is need to carry on since it is subject to some inhibitions in particular the dependence of expensively-imported Titanium (Ti) as the anode materials. The main purpose of this research was to find the best anode material as a possible subtitution which can be economically and easily to apply in Indonesia. Therefore we compared Titanium (Ti) with two other potential anodes material (Magnesium-Mg, and Aluminum (Al). The laboratory study was carried out for two days period (48 hours) in the stagnant sea water aquaria. Four aquarium tanks were treated by different electric current treatment (1 Ampere, 2 Ampere, 3 Ampere, and 5 Ampere, respectively). The reduction of electrode weigh (anode and cathode) was measured. During the experiment, water quality (i.e. $\mathrm{pH}$, and salinity) and mineral waters (calcium) were collected every 6 hour in 48 hours. The solid form of calcium carbonate was analyzed using XDS (X-ray Dispersion Spectrophotometer). The accretion rates on cathode and anode decay were compared between anodes which were treated by different electrical current. Based on the study, three anodes (aluminum, magnesium and titanium) showed different respond. Titanium and Magnesium anode showed electric current affected accretion rate $(\mathrm{P}<1)$, while for aluminum anode showed no differences on treatments.
\end{abstract}

Keywords: mineral accretion, Biorock ${ }^{\circledR}$, anode, coral reef rehabilitation, accretion rate, anode decay rate, mineral uptake

\section{INTRODUCTION}

Biorock ${ }^{\circledR}$ is using mineral accretion process and one of coral reef rehabilitation methods since late 1990s in Indonesia, which developed by Thomas Goreau, a marine biologist and Wolf Hilbertz, an engineer and architect (Hilbertz, 1979 and 1991; Bachtiar, 2003). Mineral accretion process is applying a low voltage direct electrical current through electrodes causing mineral crystals naturally found in seawater, mainly calcium carbonate and magnesium hydroxide, to grow on the structure (Hilbertz, 1979; Hartt 1984). The composite of limestone and brucite which found on the structure is similar to the composition of natural coral reefs (Lee, 2002). This solid mineral is a byproduct of $\mathrm{pH}$ changes in the cathode during the electrolysis process of sea water (Hilbertz and Goreau, 1996). This method is furthermore increase coral reef growth 3-5 times faster than the normal conditions (Lee, 2002). The associations between organisms in that structure is faster and more diverse for certain case and even can be ten times faster (Faraday, 2004).

Anode material is one of the most important parts to apply Biorock ${ }^{\circledR}$ structure. Anode defined as the electrode where the electrons come from the cell and oxidation occurs (Hastatiningsih, 1997). Anode connected to the positive 
terminal of power supply and a terminal where electrons taken from the ions in solution to facilitate chemical reactions. If the current is too high, the anode will corrode quickly (Hilbertz and Goreau, 1996). Anode material used in Biorock ${ }^{\circledR}$ structure should have high resistance to corrosion processes and have a high level of polarity due to the occurrence of oxidation reactions. In addition, $\mathrm{pH}$ values around the anode are acidic, which is potential to generate corrosion at iron, as cathode.

Titanium used as anode for the structure since its application (Lee, 2002). However, its improvement is needed to carry on since it is subject to some inhibitions in particular the dependence of expensively-imported Titanium (Ti) as the anode materials in Indonesia.

The main purpose of this research was to find the best anode material as a possible substitution which can be economically and easily to apply in Indonesia. Therefore we investigated the feasibility of Titanium (Ti) with two other potential anodes material (Magnesium-Mg, and Aluminum-Al), and treated in a different current density (1 Ampere, 2 Ampere, 3 Ampere, and 5 Ampere).

\section{METHOD}

\subsection{Preparation}

The preparations of the research are the following steps: (1) The iron stick was burnished in order to clearance the rust; (2) anode materials preparations and productions (Figure 1); (2) Wire setting on two electrodes (cathode and anode); (3) Tip of the cathode was rubbed with Resin in order to avoid corrode and the two edge of iron stick would not be covered by $\mathrm{CaCO}_{3}$ deposit; (4) Electrode numbering; and (5) Electrode weighing.

\subsection{Experiment set-up}

Cathode and anode was set on rounded wooden skeleton like a rack with space for cathode and anode on it. Anode was set on the center, and cathodes were set surround the anode with the same interval (Figure 2, left).

Each cathode wire was combined and connected to negative terminal of power supply, and anode wire was connected to positive terminal of power supply. Each wire was shield by tape. The electric current's setting and measuring was conducted after all devices submerged in the aquarium filled with sea water (Figure 2, right).

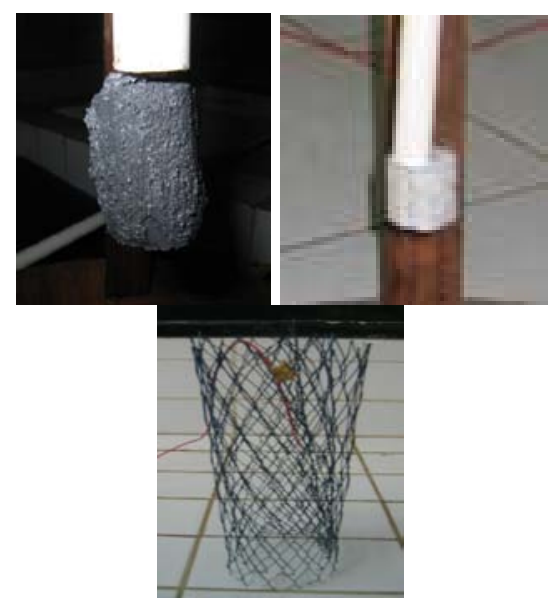

Figure 1. Anode materials used for the Biorock experiment (left: Aluminum, middle: Magnesium, right: Titanium)

\subsection{Observation and data collection}

The research was carried out for 3 months period (January to March 2006) at the Laboratory of Marine Biology, Department of Marine Science and Technology, Bogor Agricultural University. The experiment was carried out for two days (48 hours) in four aquariums, which filled with sea water and no current. Each aquarium was applied in different electric current (1 
Ampere, 2 Ampere, 3 Ampere, and 5 Ampere). Data was collected every 12 hours start from $\mathrm{t}_{0}$ (starting time) with no repetition. $\mathrm{pH}$ values were measured during the experiment.

Sample of sea water in the aquaria was collected to monitor the composition of $\mathrm{Ca}$ and $\mathrm{Mg}$ during the experiment. Water sample were put in the glass bottle and three drops of $\mathrm{HNO}_{3}$ added as sea water preservation. Then glass bottle sample was wrapped by aluminum foil paper and kept in room temperature for further analysis. Sample analysis using AAS was conducted in Environment Laboratory of Bogor Agricultural University.

Mineral solid form as accretion product was collected as dry material after 12 hours and weighted. Sample of mineral solid was collected for further mineral analysis in Metallurgy Laboratory-University of Indonesia by using XDS (X-ray Dispersion Spectrophotometer).
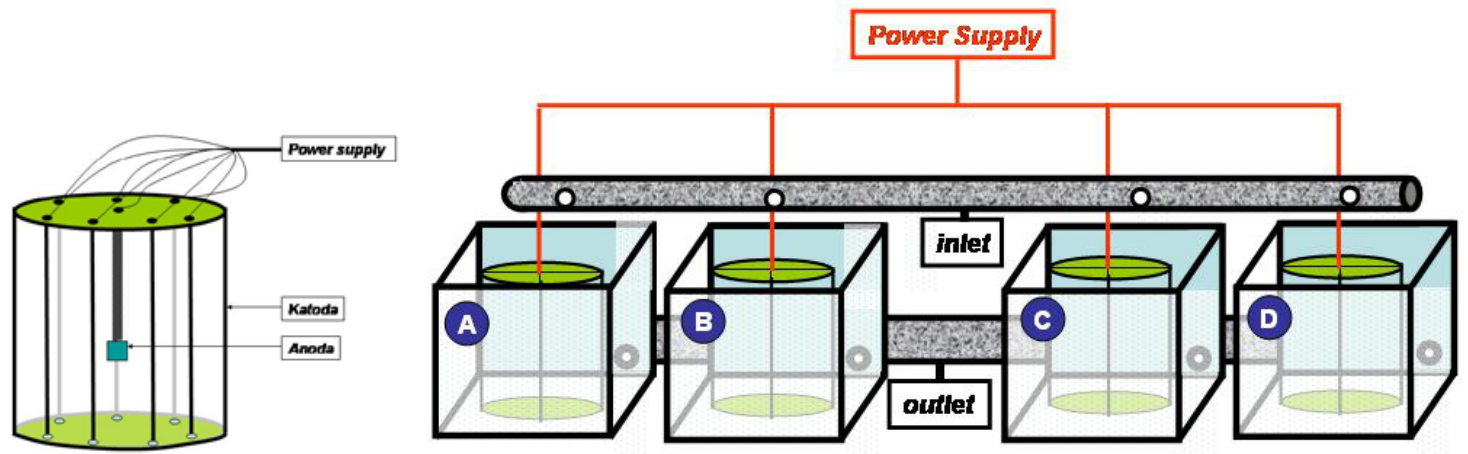

Figure 2. Schematic of electrode setting on wooden skeleton (left); and experiment setup system in four identical aquariums which treated different electrical current from power supply (right).

\subsection{Statistical analysis}

Mineral solid weight and decay rate were calculated based on the value before and after experiment in the cathode and the anode, respectively. The mineral solid weight formed and anode decay rate parameters were compared using Randomized Complete Block Design, continued with ANOVA (Analysis of Variant) and Least Significance Difference using Statistica 7 (Ashworth and Booker, 1986).

\section{RESULTS AND DISCUSSION}

\section{1. $\mathrm{pH}$ variability}

Changes of $\mathrm{pH}$ value rapidly occur in experiment treated large electrical current. This is can be found on 3 Amp and 5 Amp, while on 1 Amp and 2 Amp was slower in changes.

Sea water $\mathrm{pH}$ in the aquarium had a significant change. At the titanium and aluminum anode, $\mathrm{pH}$ had decreased from about 8 to 6 . However, the magnesium anode $\mathrm{pH}$ had tends to increased, ranged from 8.1 to 8.9 (Figure 3).

$\mathrm{pH}$ decreasing which occurred in titanium and aluminum anode because the concentration of increasing $\left[\mathrm{H}^{+}\right]$and the formation of acid. This was come from derived carbonic acid fraction and the reaction at the anode. In the ocean occurs carbonate system which maintaining the $\mathrm{pH}$ of sea water in the buffer conditions. However, in a closed and limited system (e.g. aquarium), buffer conditions would not happen. 
Therefore, there is a change of $\mathrm{pH}$ seawater.

Changes in $\mathrm{pH}$ are the result of the occurrence of electrolysis reaction at the electrode (cathode and anode). Reaction at the cathode was reduction and an alkaline, because of release $\left[\mathrm{OH}^{-}\right]$. As for what happened in the anode were the oxidation reaction and an acid because it releases $\left[\mathrm{H}^{+}\right]$. Consequently, more acidic conditions predominate in the aquarium.

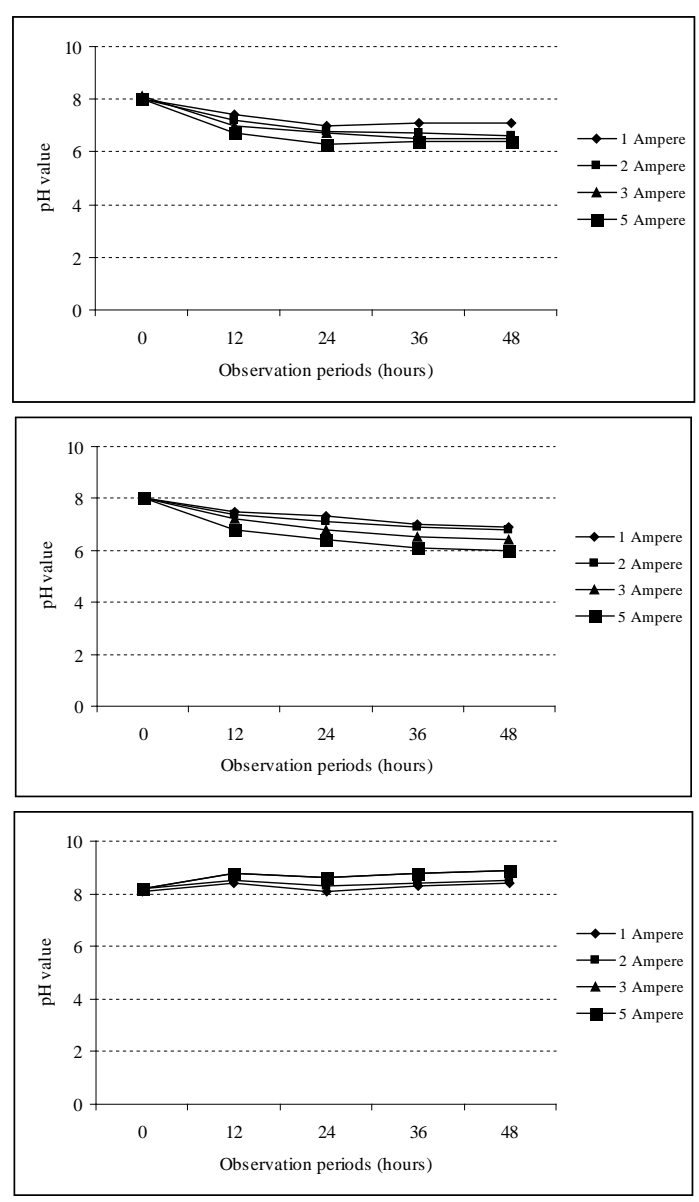

Figure 3. $\mathrm{pH}$ variability in the aquaria with Titanium anode (above), Aluminum anode (middle), and Magnesium anode (below), treated on four different electric current (1, 2, 3 and 5 Ampere).

\subsection{Calcium and Magnesium uptake}

Ca and Mg uptake value generally showed decreased on each anode (Titanium, aluminum, and Magnesium) during observation period (Figure 4 and Figure 5). The rising values of Ca uptake were on 3 Ampere at Aluminum anode, 1 Amp Magnesium anode and of $\mathrm{Mg}$ uptake was on 1 Amp Magnesium anode. Decreased value of $\mathrm{Ca}$ and $\mathrm{Mg}$ were caused by this materials were used in mineral accretion process. It applies an electric charge, causing dissolved minerals ( $\mathrm{Mg}$ and $\mathrm{Ca}$ ) to crystallize on the iron stick (cathode). Ca uptake on titanium anode ranged between 500 $800 \mathrm{mg} / \mathrm{L}$ and $\mathrm{Mg}$ uptake ranged between 140 - $160 \mathrm{mg} / \mathrm{L}$.

\subsection{Mineral element composition}

Magnesium hydroxide and calcium carbonate are one of the main components of Biorock ${ }^{\circledR}$. This composition is essentially the result of the ionic composition of seawater. Comparison between mineral compositions, Magnesium (Mg) and Calcium (Ca), which crystallized on the cathode, is shown on Figure 6. In general, Mg composition much more dominant than $\mathrm{Ca}$ on each anode samples (titanium and magnesium). This is similar to reef composition. Reef as a control for the experiment showed ratio between $\mathrm{Mg}$ and $\mathrm{Ca}$ is 2:1. Ratio of Mg:Ca which closer to reef composition is on titanium with $1 \mathrm{~A}(2: 1)$. As on titanium with 2A dan $3 \mathrm{~A}$ is $5: 1$ and 6:1, respectively. On Magnesium anode showed ratio with $1 \mathrm{~A}, 2 \mathrm{~A}$ and $3 \mathrm{~A}$ is $4: 1$, 9:1 and 33:1, respectively. 

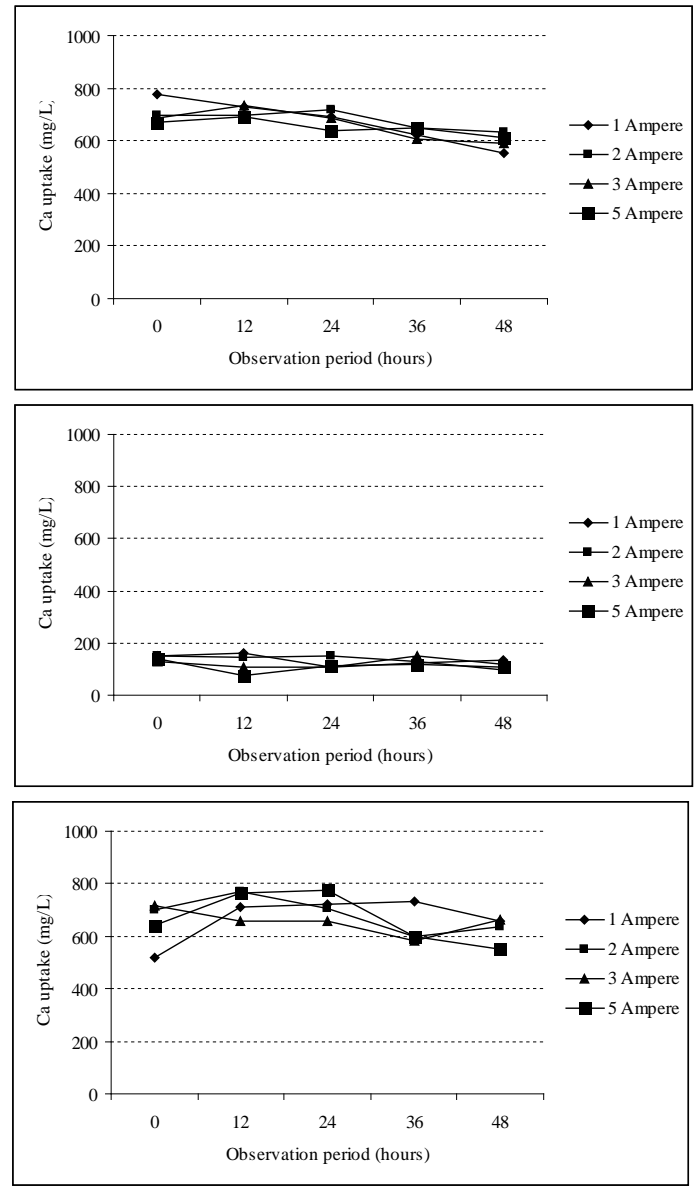

Figure 4. Calcium (Ca) uptake on three different anodes (above: Titanium, middle: Aluminium, below: Magnesium) in different electric current treatment $(1,2,3$, and 5 Ampere) during 48 hours observation period.

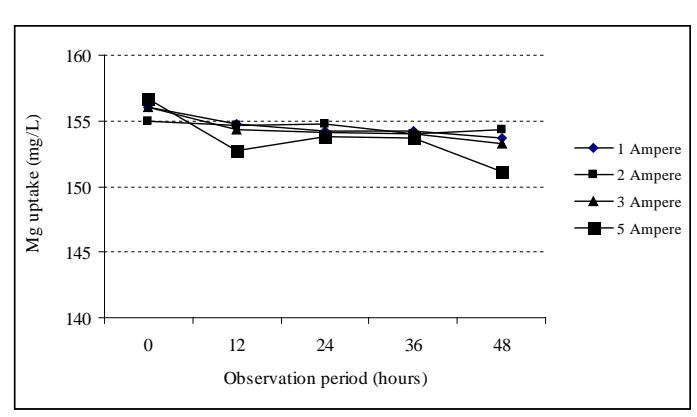

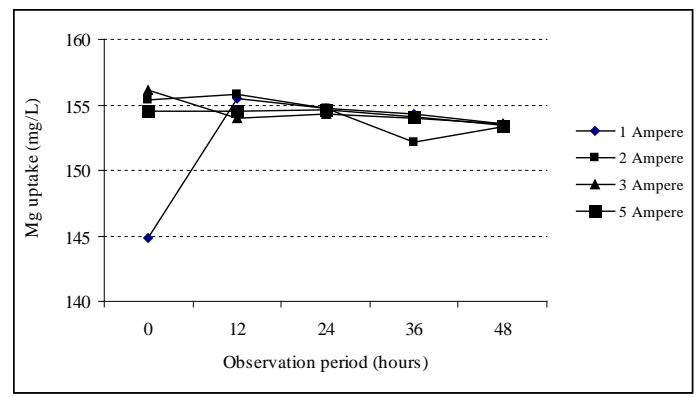

Figure 5. Magnesium (Mg) uptake on two different anodes (above: Titanium, below: Magnesium) in different electric current (1, 2, 3, and 5 Ampere) during 48 hours observation period.

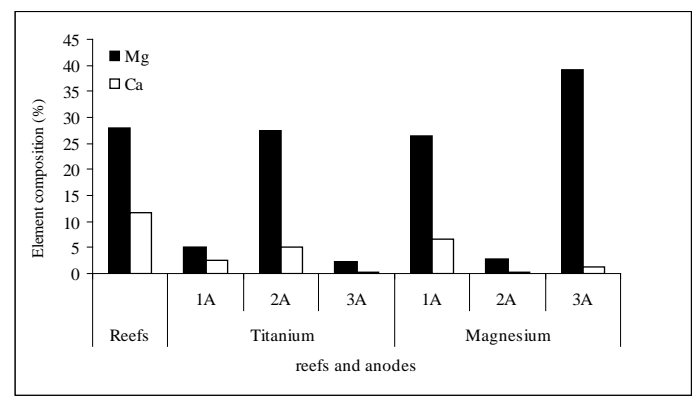

Figure 6. Element composition of Magnesium (Mg) and Calcium (Ca) at two anodes (Titanium and Magnesium) in three different current treatment (1 A, $2 \mathrm{~A}$, and 3 A), compared to reefs as control.

Highest percent element composition of $\mathrm{Mg}$ which formed become solid $\left(\mathrm{Mg}(\mathrm{OH})_{2}\right.$ ) compared to Ca which formed become $\mathrm{CaCO}_{3}$, because solubility of $\mathrm{CaCO}_{3}$ is very affected by the carbonate system in the sea water (Hilbertz, 1979; Hartt 1984). The amount of dissolved carbon dioxide in sea water declines with increasing temperature. Hence, will reduce the amount of $\mathrm{CO}_{3}{ }^{2-}$ which can be dissolved in solution. Even at a high temperature, $\mathrm{CaCO}_{3}$ will precipitated spontaneously and will be significantly at temperatures over $40^{\circ} \mathrm{C}$. 
The temperature on the aquarium experiment ranged barely between 27-28 ${ }^{\circ} \mathrm{C}$. It can be said that the level of solubility of $\mathrm{CaCO}_{3}$ decreases with the increase of sea water temperature.

\subsection{Accretion and decay rate}

Treatment of different electrical current in each anode was resulting accretion rate and anode decay rate. The rate of accretion was indicated by the number of solid minerals formed at the cathode during the process of mineral accretion. While the rate of decay showed how much part of anode waste away due to reduction reaction in the seawater.

Based on current treatment differences showed greater accretion rate along with the amount of electrical current applied to each of the anode materials. However, accretion rate on magnesium and titanium anode has decreased in the current 5 Ampere. The highest accretion rate on magnesium anode with current 3A with a value of $5.2267 \mathrm{~g} / 48$ hours. While the smallest accretion rate on titanium anode with current 1 Ampere with a value of 0.6400 $\mathrm{g} / 48$ hours. In general, magnesium anode has a large accretion rate than the other two anodes (Figure 7, above).

The rate of anode decay in accordance with the greater amount of electricity treated. In a drastic decay rate of magnesium occurs in a current of 3 Ampere and 5 Ampere with a value $17.63 \mathrm{~g} / 48$ hours and $17.83 \mathrm{~g} / 48$ hours, respectively. This is the largest rate compared with the other anodes. On titanium, decay rate has a very small and not significantly (Figure 7, below). The larger current provided will trigger a big reaction in cathode and anode. The reaction at the cathode further accelerate the accretion due to the change in $\mathrm{pH}$ value. These $\mathrm{pH}$ changes resulting from the change in hydrogen ions into hydrogen gas that spurred the formation of hydroxide ions $\left(\mathrm{OH}^{-}\right)$, resulted from the decomposition of $\mathrm{H}_{2} \mathrm{O}$ compounds. In addition carbonic acid in sea water breaks down into hydrogen ions and bicarbonate ions $\left(\mathrm{CO}_{3}{ }^{2-}\right)$, due to lack of hydrogen ions. Then the dissolved minerals in seawater changed into solid form $\mathrm{CaCO}_{3}$ and $\mathrm{Mg}(\mathrm{OH})_{2}$.

As the reaction at the anode was discard the anode increasingly due to oxidation reactions. Anode material used should have high resistance to corrosion processes and have a high level of polarity. A high level of polarity is usually indicated by a positive value galvanometric. The more positive, the material is getting stronger against the corrosion process. Aluminum and magnesium is a material with a negative value galvanimetris and include as a fully consumable metals. This material will be dissolved with electric current given. For every one or two atoms from the anode will break down into solution for each molecule formed seament. Therefore, these two materials have a large decay rate (Figure 7 , below).

Titanium anode is a fully passive type anode. This anode has a conductive coating on the surface electric. This membrane is conduction and not reactive. The only reaction that occurs from the anode of this type is the formation of gas and the decay rate is one million times lower than the fully type consumable anode metals. Therefore, in the titanium anode has a very small decay rate (Figure 7, below).

Based on ANOVA, Titanium and Magnesium anode indicated electrical current affects accretion rate $(\mathrm{P}<1)$. While on Aluminum anode showed no significantly different between electrical current treatment to accretion rate $(\mathrm{P}<1)$. Further analysis with Least Significance Difference indicated effect of electrical 
current. For all electrical current combination on Magnesium and Titanium anode showed real effect on accretion rate, unless on 3 Amp and 5 Amp. Higher current density produces faster mineral accretion rate, however the quality of the lime was unsatisfactory.
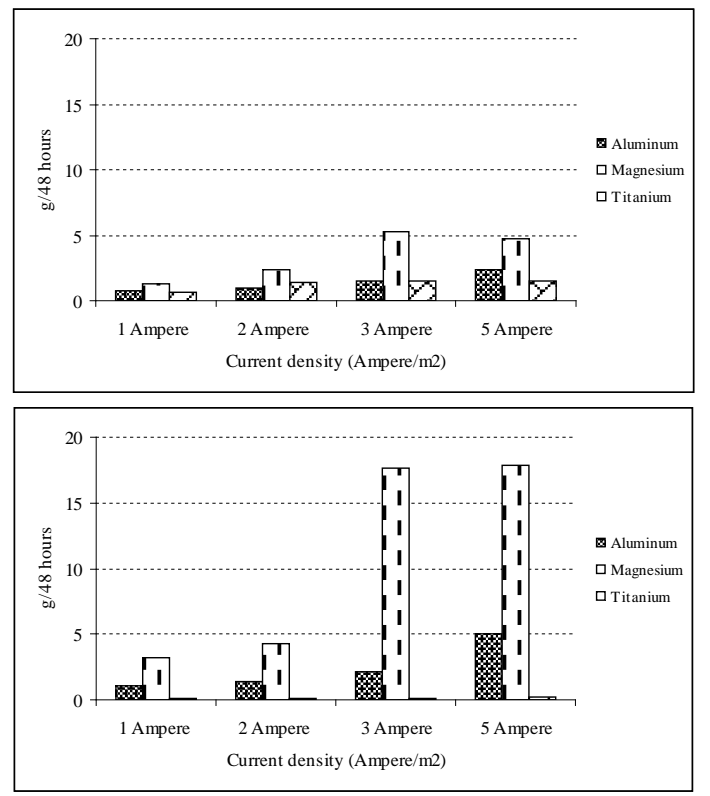

Figure 7. Accretion rate (above) and anode decay rate (below) on anode materials (Aluminum, Magnesium, and Titanium), treated with different electric current density $(1,2,3$, and 5 Ampere).

\subsection{Anode material efficiency}

The ratio of decay rate or accretion rate was used to see the efficiency of each material with electrical current treatment. Small ratio values show a better efficiency because as low decay rate can produce a large accretion rate.

Titanium anode showed the lowest ratio in the experiment. This was because of low decay rate and high accretion rate. Based on electrical current treatment the small ratio at Aluminum anode showed on 1 Amp, 2 Amp and 3 Amp; On Magnesium anode showed on 2 Amp; while on Titanium anode showed on 2 Amp and 3 Amp. Generally, all anodes showed small ratio on 2 Amp. This was a potential current for Biorock structure (Table 1).

Tabel 1. Ratio of decay rate/accretion rate on a three different anode materials (Aluminium, Magnesium, and Titanium), treated with different electric current density (1, 2, 3, and 5 Ampere)

\begin{tabular}{lcccc}
\hline Type of & \multicolumn{4}{c}{ Electrical current (Ampere) } \\
\cline { 2 - 5 } anode & 1 & 2 & 3 & 5 \\
\hline \multirow{2}{*}{ Aluminum } & 1,367 & 1,442 & 1,426 & 2,132 \\
Magnesiu & 9 & 1 & 3 & 4 \\
$\mathrm{~m}$ & 2,500 & 1,834 & 3,373 & 3,755 \\
& 0 & 9 & 5 & 7 \\
Titanium & 0,156 & 0,072 & 0,065 & 0,133 \\
& 2 & 1 & 8 & 9 \\
\hline
\end{tabular}

\section{CONCLUSION}

Based on the study, three anodes (aluminum, magnesium and titanium) showed different respond. Titanium showed the best result, followed by Magnesium Aluminum anode. The best treatment criteria are: produce the highest rate of mineral accretion, hardness level of solid minerals (known from the ratio of $\mathrm{Ca} / \mathrm{Mg}$ ), lowest anode decay rate, and the lowest oxide production. These factors were combined to get the best treatment combination.

\section{Acknowledgement}

We would like to thank Thomas Goreau (Global Coral Reef Alliance); Wolf Hilbertz (Sun \& Sea NV); Laboratory of Marine Biology, Department of Marine Science and Technology, Bogor Agricultural University; Laboratory of Metallurgy and Materials University of Indonesia; and for all people who have contributions in this research. The study was funded by Ministry of Research and Technology 
Republic Indonesia, and Indonesian Insitute of Science through research program “Riset Unggulan Terpadu 20052007”.

\section{References}

Ashworth, V. and C. J. L. Booker. 1986. Cathodic Protection: Theory and Practice. UK: Horwood Limited Chinchester.

Bachtiar, R. Pengamatan Pembentukan Terumbu Buatan dengan Metode Mineral Accretion di Desa Pemuteran, Bali Barat. Skripsi Sarjana, Jurusan Ilmu dan Teknologi Kelautan FPIK, Institut Pertanian Bogor, Indonesia, 2003.

Faraday, M. 2004. Experimental Researches in Electricity. Eighth Series. Philosophical Transactions of the Royal Society of London, 124: 425-470. StatSoft, Inc. www.statsoft.com.

Hartt. 1984. Calcareous Deposits on Metal Surfaces in Seawater - A
Critical Review. Corrosion, 40: 609-618.

Hastatiningsih. 1997. Oksidasi - Reduksi dan Elektrokimia. Bogor: Jurusan Kimia-FMIPA, Institut Pertanian Bogor.

Hilbertz, W. H. 1979. Electrodeposition of Minerals in Sea Water: Experiments and Applications. IEEE Journal on Oceanic Engineering, 4:94-113.

Hilbertz, W. H. 1991. Solar-generated construction material from sea water to mitigate global warming. Building Research and Information, 19:242-255.

Hilbertz, W. H. and T. Goreau. 1996. Method of enhancing the growth of aquatic organisms, and structures created thereby. United States Patent Number No.5 543 034.

Lee, E. R. 2002. Physics of seament electro accretion. www.stanford.edu/ [visit on 10 December 2005] 